\title{
Posições das mudas de alface nas bandejas de poliestireno e efeitos na normalidade e homogeneidade dos erros na produção de plantas ${ }^{1}$
}

\author{
Positions of lettuce seedling on polystyrene trays and effects on normality and \\ homogeneity of the errors in the plant production
}

\author{
Bernardo Zanardo², Alessandro Dal'Col Lúcio ${ }^{3 *}$, André Luiz Paludo², Daniel Santos ${ }^{4}$ e Vilson Benz ${ }^{2}$
}

\begin{abstract}
Resumo - A qualidade de um experimento pode ser descrita por intermédio de estatísticas, sendo o erro experimental um dos parâmetros de avaliação dessa qualidade. O objetivo do trabalho foi verificar a interferência de diferentes posições de mudas de alface em bandeja de poliestireno sobre a normalidade e homogeneidade dos erros em experimentos realizados em estufa plástica e em campo. Foram conduzidos seis experimentos no Departamento de Fitotecnia da Universidade Federal de Santa Maria, sendo três no verão (2006-2007) e três no outono-inverno (2007) com a cultura da alface, cultivar Vera. Os tratamentos foram 12 diferentes posições das mudas na bandeja de produção. As variáveis analisadas na produção de mudas e após o transplante aos ambientes foram a fitomassa fresca e seca da parte aérea e raiz e fitomassa fresca e seca da parte aérea, respectivamente. Foram testadas as normalidade e homogeneidade dos erros sendo comparadas às médias de cada tratamento. Há atendimento da homogeneidade e normalidade dos erros para as fitomassas fresca da parte aérea e de raiz de alface nos experimentos com diferentes posições de mudas na bandeja de produção, nos diferentes ambientes e estações sazonais de cultivo. Para a fitomassa seca da parte aérea não há atendimento da homogeneidade e/ou normalidade dos erros nos experimentos no verão, com produção de mudas e de plantas na estufa plástica. Para a fitomassa seca de raiz não há atendimento da normalidade dos erros no experimento no outono-inverno com produção de mudas.
\end{abstract}

Palavras-chave - Lactuca sativa. Planejamento experimental. Análise de variância. Mudas.

\begin{abstract}
The quality of an experiment can be described through statistics, being the experimental error one of the parameters of the evaluation of such quality. The objective of this study was to verify the interference of different positions of lettuce seedlings on polystyrene trays on the normality and homogeneity of the errors in experiments conducted in plastic greenhouse and field. Six experiments were carried out in the Federal University of Santa Maria, being three in the summer (2006-2007) and three in the autumn - winter (2007) with the lettuce crop, cultivar Vera. The treatments were defined by 12 different positions of the seedlings on the tray of production. The analyzed variables in the seedling production and after their transplant to the environments were the fresh and dry phytomass of leaves and roots and the fresh and dry phytomass of leaves, respectively. Presuppositions of errors normality and homogeneity were tested being compared to the averages of each treatment. The assumptions of homogeneity and normality of experimental errors were adequate for the leaves and root phytomass of lettuce in experiments with different positions in the tray seedling production, in different environments and cultivation seasons. For the dry phytomass of leaves trere was no adequacy of homogeneity and/or normality of experimental errors in the summer experiments, with seedlings and plants in plastic greenhouse. For the dry phytomass of root there was no adequacy of the assumption of normality of experimental error in the autumn-winter experiment with seedlings.
\end{abstract}

Key words - Lactuca sativa. Experimental planning. Analysis of variance. Seedling.

\footnotetext{
* Autor para correspondência

${ }^{1}$ Recebido para publicação em 06/04/2009; aprovado em 23/04/2010

Parte da dissertação de mestrado do primeiro autor

2Programa de Pós-Graduação em Agronomia, Universidade Federal de Santa Maria, Campus Universitário, Camobí, Santa Maria-RS, Brasil, 97105900, berzanardo@gmail.com, agropaludo@gmail.com,vibenz@gmail.com

${ }^{3}$ Departamento de Fitotecnia, Centro de Ciências Rurais, Universidade Federal de Santa Maria, Campus Universitário, Camobí, Santa Maria-RS, Brasil, 97105-900, adlucio@smail.ufsm.br

${ }^{4}$ Curso de graduação em Agronomia, Universidade Federal de Santa Maria, Campus Universitário, Camobí, Santa Maria-RS, Brasil, 97105-900, daniel_agronomo@yahoo.com.br
} 


\section{Introdução}

No Brasil a alface é a hortaliça folhosa mais consumida (YURI et al., 2002) sendo considerada uma das principais espécies hortícolas cultivadas, tanto do ponto de vista econômico como de consumo (GOTO, 1998). A cultura é de fácil manejo, ciclo curto, alta produtividade e rápido retorno financeiro, tendo maior número de cultivos por ano em relação a outras hortaliças (BACKES et al., 2003). A propagação é via sementes e a germinação condicionada pela temperatura, umidade e radiação. Por serem sementes de pequeno porte, possuem poucas reservas, exigindo condições otimizadas para a germinação a fim de assegurar a emergência e produção de mudas de alto vigor. Porém Marques et al. (2003) observaram desuniformidade do estande de plantas na emergência das plântulas, provavelmente oriundas da heterogeneidade do sistema, da variabilidade das diferentes posições das mudas dentro das bandejas de poliestireno e das possíveis diferenças das plantas no estabelecimento da população.

A uniformidade entre as mudas pode ser afetada pelo tempo de permanência na bandeja, pelo volume de substrato e pela competição entre suas partes aéreas. Andriolo et al. (2003) verificaram que as mudas de alface transplantadas precocemente e com menor tamanho e desenvolvimento induziram um menor crescimento e desenvolvimento em relação àquelas provindas de mudas transplantadas tardiamente e com maior tamanho e desenvolvimento. Também observaram que o crescimento das raízes afetou o crescimento da parte aérea das mudas de alface, sugerindo que para a produção de mudas de alta qualidade fisiológica, devese estabelecer um tamanho mínimo dos alvéolos não afetando o crescimento da parte aérea.

Em cultivos de olerícolas em ambiente protegido, fatores como a proximidade das linhas de cultivo com as laterais da estufa, a presença ou ausência de frutos colhidos, as múltiplas colheitas realizadas, o manejo cultural intensivo como adubações, irrigações controle de pragas, doenças e plantas daninhas e o maior fluxo de pessoas entre as linhas de cultivo são fontes de variabilidade e de não normalidade dos erros experimentais, que devem ser controladas na execução de experimentos nesses ambientes de cultivo (CARPES et al., 2008; FEIJÓ et al., 2008; LORENTZ et al., 2004; LORENTZ et al., 2005; LÚCIO et al., 2004; LÚCIO et al., 2006; LÚCIO et al., 2008; MELLO et al., 2004; SOUZA et al., 2002). A heterogeneidade e não normalidade dos erros podem também ser causados, inicialmente, pela utilização de mudas heterogêneas dentro da mesma linha de cultivo e entre linhas. Isso poderá influenciar nas informações obtidas em relação às técnicas experimentais, principalmente em experimentos onde o material experimental é constituído por mudas que podem se apresentar heterogêneas entre si, inflacionando assim o erro experimental. O estudo deste erro nessas condições é necessário, pois a ocorrência da homogeneidade das variâncias residuais valida a análise de variâncias e assegura o nível de significância dos testes F e de médias (BANZATTO; KRONKA, 1995). Assim, a presença da variabilidade em níveis significativos na produção das mudas poderá induzir a um maior erro experimental quando em experimentos em estufa plástica e a campo, mascarando resultados e obtendo conclusões imprecisas.

Com essas características inerentes a esse sistema de cultivo, há a necessidade de caracterizar a fonte de variabilidade mais proeminente e planejar experimentos de tal forma a mantê-la sob controle. Diante disso, o objetivo do trabalho foi verificar a interferência de diferentes posições de mudas de alface nas bandejas de poliestireno, sobre a normalidade e a homogeneidade dos erros em experimentos realizados em diferentes ambientes e épocas de cultivo.

\section{Material e métodos}

Foram conduzidos seis experimentos com a cultura da alface, cultivar Vera, nas estações verão (2006-2007) e outono-inverno (2007) no Departamento de Fitotecnia da Universidade Federal de Santa Maria, com coordenadas geográficas de 294'23' S e 53\%43'15', W e altitude de $95 \mathrm{~m}$. Destes, dois com a produção de mudas e dois com produção de plantas foram realizados em estufa plástica e os outros dois de produção de plantas foram realizados em campo. O clima da região é classificado como Cfa subtropical úmido, sem estação seca e com verões quentes, conforme a classificação de Köppen (MORENO, 1961) e o solo classificado como Argissolo Vermelho Distrófico Arênico (EMBRAPA, 1999).

A semeadura foi realizada em bandejas de poliestireno com 200 células, empregando o substrato comercial Plantmax $^{\circledR}$. Durante o período entre a semeadura e a avaliação das mudas, as bandejas permaneceram sobre estrados a um metro do solo, no interior de uma casa de vegetação de vidro orientada na direção Leste-Oeste. Para a irrigação foi utilizado o sistema de microaspersão, de forma a manter sempre elevado o teor de umidade do substrato, conforme as necessidades da cultura. As avaliações foram realizadas quando as mudas de alface estavam no estádio de três a quatro folhas definitivas.

Nos experimentos de produção de plantas em estufa plástica foi utilizada uma estufa de 19,5 m de comprimento, $10 \mathrm{~m}$ de largura, orientação longitudinal na direção NorteSul e constituída por estrutura de metal galvanizado na forma de arco pampeano, coberta com filme e polietileno de baixa densidade (PEBD) de 100 micras. A ventilação foi realizada através da abertura das cortinas laterais e portas de acordo com as condições meteorológicas do dia. Nos dias 
ensolarados, procedeu-se à abertura no início da manhã e o fechamento ao final da tarde, independente da estação de cultivo. Nos dias chuvosos ou ventosos, a estufa permaneceu fechada. Para os experimentos de produção de plantas em campo, a área experimental utilizada teve as mesmas dimensões da estufa plástica. Em ambos os casos as linhas de cultivo foram orientadas na direção Norte-Sul.

O preparo do solo, a correção da acidez e a aplicação de fertilizantes foram realizadas de acordo com a análise de solo e recomendações para a cultura de acordo com o Manual de Adubação e Calagem para os Estados do Rio Grande do Sul e Santa Catarina (2004). A irrigação nos experimentos em campo e em estufa plástica foi realizada por gotejamento, utilizando-se mangas com gotejadores espaçados $30 \mathrm{~cm}$ entre si.

Os experimentos em casa de vegetação para a produção de mudas foram compostos por doze tratamentos constituídos de diferentes posições de mudas de alface em bandejas de poliestireno (Figura 1), sendo aplicado o delineamento inteiramente casualizado com quatro repetições em casa de vegetação. Após, as mudas foram levadas para a estufa plástica e o campo, sob o delineamento em blocos ao acaso, constituído de seis repetições em estufa plástica e seis repetições a campo, na estação verão.

Bordadura X Centro Direita X Centro X Esquerda

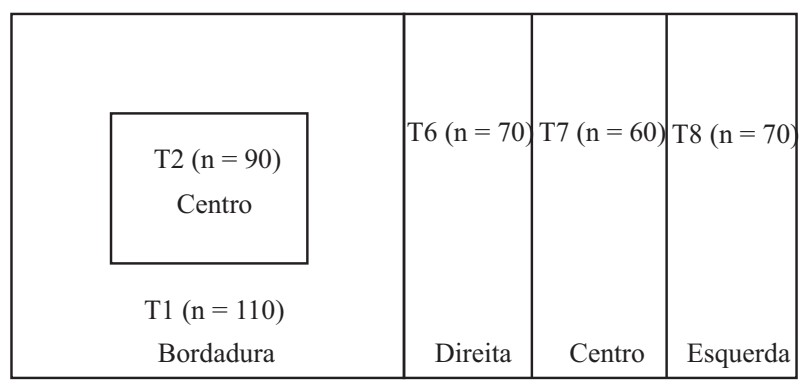

Frente X Centro X Fundo

\begin{tabular}{|c|c|c|}
\hline $\begin{array}{c}\text { T3 }(\mathrm{n}=60) \\
\text { Frente }\end{array}$ & \multirow{2}{*}{$\mathrm{T} 9(\mathrm{n}=50)$} & $\mathrm{T} 10(\mathrm{n}=50)$ \\
\cline { 1 - 1 } $\mathrm{T} 4(\mathrm{n}=80)$ & Quadrante 1 & Quadrante 2 \\
Centro & $\mathrm{T} 11(\mathrm{n}=50)$ & $\mathrm{T} 12(\mathrm{n}=50)$ \\
T5 (n=60) & & \\
Fundo & Quadrante 3 & Quadrante 4 \\
\hline
\end{tabular}

Figura 1 - Disposição dos tratamentos das mudas de alface em bandejas de poliestireno, com diferentes números de unidades básicas (n) por tratamento simulado. Santa Maria, RS, 2008
Cada repetição foi constituída de uma linha de cultivo contendo 48 plantas espaçadas a $0,3 \mathrm{~m}$ na linha e $0,8 \mathrm{~m}$ na entrelinha, sendo a unidade básica composta por quatro plantas. Para a estação outono-inverno foi modificado apenas o número de repetições: seis em estufa plástica e três a campo. As demais informações foram idênticas à estação verão.

Nos experimentos com produção de mudas as variáveis observadas foram as fitomassas fresca e seca da parte aérea e raiz (FFPA, FSPA, FFR e FSR) enquanto que nos experimentos na estufa plástica e campo foram apenas as fitomassas fresca e seca da parte aérea (FFPA e FSPA), sendo as massas determinadas, em gramas, com a utilização de uma balança digital. As fitomassas fresca da produção das mudas foram determinadas no início da manhã e da estufa plástica e do campo no final da tarde, para a estação verão. Na estação outono-inverno, todas as determinações das fitomassas fresca ocorreram no final da tarde. Na determinação da fitomassa seca as plantas foram colocadas em estufa a $60{ }^{\circ} \mathrm{C}$, sendo retiradas quando apresentaram fitomassa constante.

Foram avaliadas quatro plantas por posição em cada repetição para a determinação da fitomassa fresca e seca nas bandejas de poliestireno na produção de mudas. Nos ambientes estufa plástica e campo foram avaliadas 48 plantas de cada posição por repetição para a fitomassa fresca. Para a determinação da fitomassa seca, apenas uma planta das 48 foi selecionada ao acaso para a avaliação.

Foram estimadas as variâncias de cada tratamento e testadas a homogeneidade e normalidade dos erros do modelo matemático, via testes de Bartlett (STELL et al., 1997) e Lilliefors (CAMPOS, 1983), respectivamente, para cada estação de cultivo. Também foi realizada a análise de variância com teste $\mathrm{F}$, em cada experimento individual para as duas estações de cultivo e as médias dos tratamentos foram comparadas pelo teste ScottKnott. Em todas as análises estatísticas adotou-se 5\% de probabilidade de erro.

\section{Resultados e discussão}

Após a aplicação do teste de Bartlett verificou-se que, na estação verão, as variâncias foram homogêneas nos ambientes de estufa plástica e campo em ambas as variáveis. No experimento de produção de mudas uma das quatro variáveis testadas não apresentou homogeneidade de variâncias. No outono-inverno, observou-se que as variâncias foram homogêneas para todas as variáveis testadas, independente do ambiente de cultivo (Tabela 1). Para a condição de normalidade, as variáveis fitomassa seca da parte aérea (FSPA) do ambiente estufa plástica na estação verão e fitomassa seca da raiz (FSR) do ambiente casa de 
vegetação na estação outono-inverno não foram atendidas (Tabela 1). Como os experimentos foram conduzidos de forma em que a colheita ocorresse no mesmo dia para todas as plantas, as pressuposições de homogeneidade e normalidade dos erros não foram satisfeitas em $12,5 \%$ nas variáveis dos experimentos do verão e 0 e $12,5 \%$, para homogeneidade e normalidade dos erros respectivamente, nas variáveis dos experimentos do outono-inverno. Essa baixa percentagem não afeta significativamente a análise paramétrica dos dados e as estatísticas que utilizam o quadrado médio do erro e que determinam a confiabilidade dos resultados gerados. Assim, não há necessidade de

Tabela 1 - Variâncias das fitomassas fresca e seca da parte aérea (FFPA e FSPA) e sistema radicular (FFR e FSR) das mudas e das plantas de alface (g planta $\left.{ }^{-1}\right)$ nas estações verão (2006-2007) e outono-inverno (2007)

\begin{tabular}{|c|c|c|c|c|c|c|c|c|}
\hline \multirow{3}{*}{ Tratamentos } & \multirow{2}{*}{\multicolumn{4}{|c|}{$\begin{array}{c}\text { Estufa plástica } \\
\text { Mudas }\left(\mathrm{g} \times 10^{-5}\right)\end{array}$}} & \multicolumn{4}{|c|}{ Produção de plantas } \\
\hline & & & & & \multicolumn{2}{|c|}{ Estufa } & \multicolumn{2}{|c|}{ Campo } \\
\hline & FFPA & FSPA & FFR & FSR & FFPA & FSPA & FFPA & FSPA \\
\hline \multicolumn{9}{|c|}{ Verão } \\
\hline Bordadura (T1) & 5316,26 & 39,98 & 1862,92 & 6,82 & 1621,34 & 6,17 & 1540,64 & 8,17 \\
\hline Centro (T2) & 17137,24 & 187,92 & 2905,42 & 14,32 & 2609,79 & 10,67 & 1630,72 & 7,90 \\
\hline Frente (T3) & 2538,75 & 596,08 & 1170,57 & 10,57 & 3003,42 & 9,87 & 1317,73 & 6,17 \\
\hline Centro (T4) & 6049,67 & 62,24 & 1825,42 & 0,83 & 1438,09 & 21,87 & 918,26 & 4,67 \\
\hline Fundo (T5) & 3145,21 & 2,66 & 2172,24 & 4,32 & 3424,07 & 26,57 & 2430,57 & 14,27 \\
\hline Esquerda (T6) & 4266,82 & 9,38 & 180,99 & 14,17 & 6778,84 & 14,27 & 2278,64 & 13,07 \\
\hline Centro (T7) & 680,62 & 16,82 & 769,58 & 1,08 & 6175,42 & 4,97 & 627,19 & 5,47 \\
\hline Direita (T8) & 7250,57 & 77,66 & 1886,41 & 3,07 & 1495,69 & 0,70 & 1944,05 & 10,40 \\
\hline Quadrante 1 (T9) & 3393,75 & 65,42 & 974,74 & 18,20 & 2346,21 & 8,17 & 839,64 & 5,47 \\
\hline Quadrante 2 (T10) & 3964,38 & 15,63 & 130,42 & 10,57 & 1903,92 & 4,97 & 1857,77 & 10,40 \\
\hline Quadrante 3 (T11) & 115,57 & 23,07 & 1013,77 & 6,04 & 1316,67 & 11,07 & 782,67 & 1,60 \\
\hline Quadrante 4 (T12) & 5285,42 & 181,04 & 862,66 & 1,04 & 1954,26 & 9,60 & 1315,33 & 6,17 \\
\hline Homogeneidade $^{1}$ & SIM & NÃO & SIM & SIM & SIM & SIM & SIM & SIM \\
\hline Normalidade $^{2}$ & SIM & SIM & SIM & SIM & SIM & $\mathrm{NÃO}$ & SIM & SIM \\
\hline \multicolumn{9}{|c|}{ Outono-inverno } \\
\hline Bordadura (T1) & 12910,22 & 48,82 & 1975,16 & 2,77 & 364,78 & 5,73 & 608,15 & 6,00 \\
\hline Centro (T2) & 17116,89 & 64,89 & 1410,16 & 15,23 & 346,09 & 3,83 & 881,02 & 5,54 \\
\hline Frente (T3) & 6504,56 & 41,09 & 1951,25 & 6,47 & 268,42 & 2,73 & 463,52 & 4,59 \\
\hline Centro (T4) & 9422,29 & 38,47 & 1472,71 & 24,63 & 451,02 & 7,45 & 217,58 & 4,29 \\
\hline Fundo (T5) & 1937,89 & 13,27 & 1330,99 & 4,10 & 240,50 & 3,25 & 150,81 & 0,65 \\
\hline Esquerda (T6) & 18787,42 & 5,10 & 581,41 & 23,10 & 259,37 & 1,50 & 276,94 & 3,31 \\
\hline Centro (T7) & 27474,93 & 35,63 & 2402,29 & 10,56 & 196,12 & 4,93 & 578,77 & 0,23 \\
\hline Direita (T8) & 14347,60 & 12,42 & 2225,57 & 1,10 & 345,49 & 2,81 & 215,06 & 0,77 \\
\hline Quadrante 1 (T9) & 14987,56 & 47,29 & 1692,29 & 5,80 & 860,64 & 4,90 & 156,44 & 4,02 \\
\hline Quadrante 2 (T10) & 29368,37 & 37,09 & 2013,49 & 3,22 & 542,94 & 3,39 & 204,02 & 3,47 \\
\hline Quadrante 3 (T11) & 18209,23 & 11,77 & 367,92 & 1,27 & 766,40 & 4,28 & 427,69 & 0,80 \\
\hline Quadrante 4 (T12) & 25814,23 & 20,10 & 761,04 & 1,77 & 674,27 & 2,61 & 310,58 & 10,92 \\
\hline Homogeneidade $^{1}$ & SIM & SIM & SIM & SIM & SIM & SIM & SIM & SIM \\
\hline Normalidade $^{2}$ & SIM & SIM & SIM & NÃO & SIM & SIM & SIM & SIM \\
\hline
\end{tabular}

${ }^{1}$ Homogeneidade dos erros experimentais pelo teste de Bartlett, em nível 5\% de probabilidade de erro; ${ }^{2}$ Normalidade dos erros experimentais pelo teste de Lilliefors, em nível 5\% de probabilidade de erro 
utilizar a análise não-paramétrica e a transformação dos dados em uma nova escala para essas variáveis observadas em experimentos com alface.

A heterogeneidade das variâncias para a fitomassa seca da parte aérea (FSPA) na estação verão pode ser atribuída também a fatores como as variações ocorridas na disposição dos tratamentos na casa de vegetação e eventuais desuniformidades ocorridas na secagem do material em estufa a $60{ }^{\circ} \mathrm{C}$. A amplitude das variâncias observadas entre as variáveis FFPA e FSPA (Tabela 1) pode estar relacionadas ao conteúdo de água que varia entre uma planta e outra.

Apesar da constatação de homogeneidade das variâncias quase que na totalidade das variáveis avaliadas, independente do experimento e da estação de cultivo, observou-se que as maiores variâncias obtidas no experimento com produção de mudas não se mantiveram elevadas após o transplante destas e o estabelecimento das plantas na estufa plástica e campo (Tabela 1 ). O tratamento centro T2, por exemplo, que resultou em maior variância para a variável fitomassa fresca da parte aérea (FFPA) durante a produção de mudas na estação verão $(0,17 \mathrm{~g})$ não apresentou o valor mais elevado para estufa plástica $(2.609,79 \mathrm{~g})$ e campo $(1.630,72 \mathrm{~g})$ para a mesma variável (Tabela 1). Para o outono-inverno, observou-se situação semelhante para a mesma posição, nas mesmas condições informadas acima, somente com valores diferenciados de variâncias (Tabela 1).

A normalidade dos erros, nas variáveis onde essa pressuposição não foi atendida (Tabela 1), pode ter sido afetada pelas variâncias obtidas nos tratamentos T5 e T6 (maiores) e T8 (menor), na FSPA do experimento da estufa plástica no verão. Já para a variável FSR do experimento com produção de mudas no outono-inverno, os tratamentos T4 e T6 foram os que apresentaram as maiores variâncias e T8, T11 e T12 as menores. Em ambos os casos, a falta de normalidade dos erros foi provocada pelos valores extremos da variância residual dos tratamentos citados dentro de cada variável. Esses extremos de valores altos e baixos para a estimativa da variância residual dos tratamentos fez com que a distribuição dos erros se tornasse assimétrica.

A heterogeneidade e a não normalidade dos erros experimentais nos experimentos de produção de mudas e de produção de plantas de alface não se caracterizou como um problema, uma vez que, no trabalho, foram utilizadas sementes de uma mesma cultivar, portanto geneticamente homogênea. A presença de heterogeneidade e não normalidade dos erros presentes nos experimentos deve ter sido devido a fatores ambientais, podendo ser considerados aleatórios. As variações com o uso da bandeja de poliestireno também são minimizadas, pois estas apresentam superfície uniforme, alvéolos de mesmos tamanhos e uniformemente distribuídos e homogeneidade de volume e materiais empregados como substrato.

Na estufa plástica e no campo deve ser considerado que a cultura avaliada é uma planta de ciclo biológico curto e que apresenta um único ponto de colheita. Isso permite inferir que um dos principais atributos para o crescimento e desenvolvimento da cultivar de alface Vera, ou seja, a condição meteorológica reflita de forma semelhante nas variáveis estudadas, já que essas são avaliadas em um mesmo período (dia), diferentemente de culturas olerícolas em que as variáveis estudadas são as produções de fitomassa dos frutos, os quais surgem em períodos diferentes de uma planta para a outra pelas diferenças diárias na temperatura do ar, brilho solar e umidade relativa, alterando diretamente a fisiologia da planta e variabilidade do sistema produtivo. Lorentz et al. (2004) e Carpes et al. (2008) verificaram que um dos principais fatores de erro é a interferência do pesquisador no momento da colheita, ou seja, estes podem interpretar de forma diferente esta etapa do experimento, vindo interferir significativamente nas variáveis analisadas e na interpretação dos resultados.

A variabilidade oriunda das fases iniciais dos experimentos, como na semeadura e obtenção de mudas ou mesmo no transplante pode contribuir significativamente para o acréscimo do erro experimental, conforme relata Lorentz et al. (2004). Essa situação pode ser descartada no presente trabalho pela constatação de homogeneidade e normalidade dos erros na maioria dos casos. Isso indica que para a cultura da alface cultivar Vera, não há necessidade de discriminar as diferentes posições das mudas para serem transplantadas nos ambientes definitivos de produção.

Na comparação das médias para a estação sazonal verão, de todas as variáveis avaliadas nos diferentes experimentos, as variáveis fitomassa fresca da raiz (FFR) no experimento com produção de mudas e a fitomassa seca da parte aérea (FSPA) no experimento no campo, não apresentaram diferenças significativas entre as médias dos tratamentos (Tabelas 2 e 3).

Já na estação outono-inverno, somente a variável FFPA do ambiente estufa plástica, apresentou diferenças significativas entre as médias de produção testadas (Tabela 3). A variável FSPA do mesmo ambiente e as demais variáveis dos experimentos de produção de mudas e em campo, respectivamente, não apresentaram diferenças significativas (Tabelas 2 e 3 ).

Nos experimentos de produção de mudas, apesar de não existirem diferenças significativas, as médias das variáveis FFPA e FFR das posições foram maiores em relação à avaliação da estação sazonal verão. Isso ocorre devido a temperatura média diária do ar ter se mantido na faixa dos 20 a $25^{\circ} \mathrm{C}$ para a produção de mudas (Figura 2) e 
Tabela 2 - Fitomassa fresca e seca da parte aérea (FFPA e FSPA) e raiz (FFR e FSR), em g planta ${ }^{-1}$ de mudas de alface produzidas em estufa plástica nas estações verão (2006-2007) e outono-inverno (2007)

\begin{tabular}{|c|c|c|c|c|c|c|c|c|}
\hline \multirow{2}{*}{ Tratamentos } & \multicolumn{4}{|c|}{ Verão } & \multicolumn{4}{|c|}{ Outono-inverno } \\
\hline & FFPA & FSPA & FFR & FSR & FFPA & FSPA & FFR & FSR \\
\hline Bordadura (T1) & $1,19 b^{*}$ & $0,14 \mathrm{~b}$ & $0,44 \mathrm{~b}$ & $0,04^{\text {ns }}$ & $2,21^{\mathrm{ns}}$ & $0,09^{\text {ns }}$ & $0,61^{\mathrm{ns}}$ & $0,02^{\text {ns }}$ \\
\hline Centro (T2) & $1,79 \mathrm{a}$ & $0,18 \mathrm{a}$ & $0,66 \mathrm{a}$ & 0,06 & 2,44 & 0,10 & 0,71 & 0,03 \\
\hline Frente (T3) & $1,65 \mathrm{a}$ & $0,17 \mathrm{a}$ & $0,52 \mathrm{a}$ & 0,04 & 2,13 & 0,08 & 0,65 & 0,02 \\
\hline Centro (T4) & $1,53 \mathrm{a}$ & $0,13 \mathrm{~b}$ & $0,57 \mathrm{a}$ & 0,04 & 2,34 & 0,08 & 0,78 & 0,02 \\
\hline Fundo (T5) & $1,61 \mathrm{a}$ & $0,13 \mathrm{~b}$ & $0,60 \mathrm{a}$ & 0,05 & 2,31 & 0,08 & 0,61 & 0,02 \\
\hline Esquerda (T6) & $1,38 \mathrm{~b}$ & $0,11 \mathrm{~b}$ & $0,47 \mathrm{~b}$ & 0,05 & 2,20 & 0,07 & 0,59 & 0,02 \\
\hline Centro (T7) & $1,07 \mathrm{~b}$ & $0,09 \mathrm{~b}$ & $0,42 \mathrm{~b}$ & 0,03 & 2,48 & 0,10 & 0,75 & 0,03 \\
\hline Direita (T8) & $1,62 \mathrm{a}$ & $0,13 \mathrm{~b}$ & $0,50 \mathrm{~b}$ & 0,04 & 2,13 & 0,07 & 0,63 & 0,02 \\
\hline Quadrante 1 (T9) & $1,32 \mathrm{~b}$ & $0,10 \mathrm{~b}$ & $0,41 \mathrm{~b}$ & 0,05 & 2,45 & 0,09 & 0,59 & 0,02 \\
\hline Quadrante 2 (T10) & $1,17 \mathrm{~b}$ & $0,11 \mathrm{~b}$ & $0,40 \mathrm{~b}$ & 0,05 & 2,39 & 0,09 & 0,69 & 0,02 \\
\hline Quadrante 3 (T11) & $1,29 \mathrm{~b}$ & $0,13 \mathrm{~b}$ & $0,41 \mathrm{~b}$ & 0,05 & 2,38 & 0,09 & 0,61 & 0,02 \\
\hline Quadrante 4 (T12) & $1,39 \mathrm{~b}$ & $0,15 \mathrm{~b}$ & $0,37 \mathrm{~b}$ & 0,05 & 2,45 & 0,10 & 0,68 & 0,01 \\
\hline Média & 1,42 & 0,12 & 0,48 & 0,04 & 2,33 & 0,08 & 0,65 & 0,03 \\
\hline CV $(\%)$ & 15,65 & 25,15 & 22,17 & 17,83 & 17,42 & 20,22 & 18,76 & 44,35 \\
\hline
\end{tabular}

*Médias dos tratamentos com as letras diferentes, dentro de cada variável e cada estação, diferem pelo teste Scott-Knott em nível de $5 \%$ de probabilidade de erro; ns: não significativo

a produção regular da cultura da alface ser comprometida com temperaturas acima de $25^{\circ} \mathrm{C}$ (SILVA et al., 1999).

Essa situação não ocorreu no cultivo de verão, onde as temperaturas do ar e a radiação solar foram elevadas (Figura 2), favorecendo um rápido desenvolvimento das mudas induzindo as plantas ao pendoamento precoce, conforme relatam Segovia et al. (1997). No entanto, as médias dos ambientes de produção (estufa plástica e campo) foram inferiores. O brilho solar e a temperatura do ar nesse período diminuíram (Figura 2) o que pode causar efeitos no processo de fotossíntese e, consequentemente, na produção de fitomassa das plantas. Como a quantidade de radiação solar incidente é diferenciada entre os ambientes de produção e para as diferentes estações de cultivo, essa interfere no crescimento, desenvolvimento, armazenamento de açúcares e consumo de água da cultura (GATES, 2008) influenciando na produção de fitomassa fresca e seca.

As variações ocorridas na média e na variância não foram proporcionais, ou seja, a posição que resultou em maior média necessariamente não apresentou a maior variância. Na estação verão, na estufa plástica, por exemplo, o tratamento frente que resultou em maior estimativa da média (312,62 g - Tabela. 3), não apresentou maior variância $(3.003,42 \mathrm{~g}$ - Tabela 1$)$, para a variável fitomassa fresca da parte aérea. Para a estação outono-
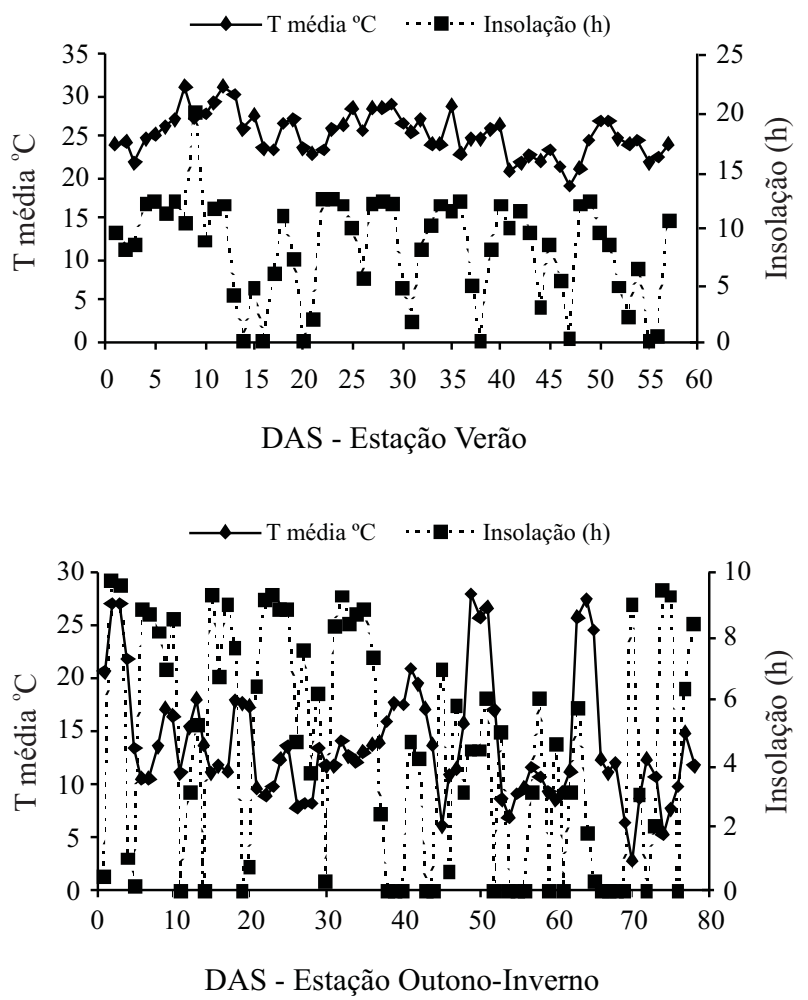

Figura 2 - Temperatura média do ar $\left({ }^{\circ} \mathrm{C}\right)$ e insolação (h) nos dias após a semeadura (DAS) em Santa Maria-RS, durante a execução dos experimentos com alface nas duas estações de cultivo 
Tabela 3 - Fitomassa fresca e seca da parte aérea (FFPA e FSPA), em g.planta-1 ${ }^{1}$, de plantas de alface produzidas em estufa plástica e a campo, nas estações verão (2006-2007) e outono-inverno (2007)

\begin{tabular}{|c|c|c|c|c|}
\hline \multirow{2}{*}{ Tratamentos } & \multicolumn{2}{|c|}{ Verão } & \multicolumn{2}{|c|}{ Outono-inverno } \\
\hline & FFPA & FSPA & FFPA & FSPA \\
\hline \multicolumn{5}{|c|}{ Estufa plástica } \\
\hline Bordadura (T1) & $253,55 \mathrm{a}^{*}$ & $16,17 \mathrm{a}$ & $116,00 \mathrm{~b}$ & $11,23^{\mathrm{ns}}$ \\
\hline Centro (T2) & $239,55 \mathrm{a}$ & $14,33 \mathrm{a}$ & $139,95 \mathrm{a}$ & 10,77 \\
\hline Frente (T3) & $312,62 \mathrm{a}$ & $18,67 \mathrm{a}$ & $119,42 \mathrm{~b}$ & 10,64 \\
\hline Centro (T4) & $247,95 \mathrm{a}$ & $13,67 \mathrm{~b}$ & $137,33 \mathrm{a}$ & 10,14 \\
\hline Fundo (T5) & $294,12 \mathrm{a}$ & $18,17 \mathrm{a}$ & $109,25 \mathrm{~b}$ & 10,35 \\
\hline Esquerda (T6) & $264,33 \mathrm{a}$ & $16,33 \mathrm{a}$ & $103,83 \mathrm{~b}$ & 10,66 \\
\hline Centro (T7) & 253,67 a & $16,17 \mathrm{a}$ & $133,17 \mathrm{a}$ & 11,13 \\
\hline Direita (T8) & 239,17 a & $13,50 \mathrm{~b}$ & $114,71 \mathrm{~b}$ & 10,90 \\
\hline Quadrante 1 (T9) & $226,80 \mathrm{a}$ & $12,83 \mathrm{~b}$ & $111,62 b$ & 10,23 \\
\hline Quadrante 2 (T10) & $169,12 \mathrm{~b}$ & $9,83 \mathrm{~b}$ & $130,83 \mathrm{a}$ & 10,92 \\
\hline Quadrante 3 (T11) & $172,87 \mathrm{a}$ & $12,33 \mathrm{~b}$ & $132,00 \mathrm{a}$ & 11,18 \\
\hline Quadrante 4 (T12) & $178,80 \mathrm{a}$ & $12,00 \mathrm{~b}$ & $133,12 \mathrm{a}$ & 11,39 \\
\hline Média & 237,71 & 14,50 & 123,43 & 10,79 \\
\hline $\mathrm{CV}(\%)$ & 22,47 & 21,88 & 14,31 & 16,13 \\
\hline \multicolumn{5}{|c|}{ Campo } \\
\hline Bordadura (T1) & $90,67 \mathrm{~b}$ & $7,17^{\text {ns }}$ & $64,67^{\text {ns }}$ & $6,73^{\text {ns }}$ \\
\hline Centro (T2) & $75,67 \mathrm{~b}$ & 6,50 & 77,08 & 9,02 \\
\hline Frente (T3) & $101,50 \mathrm{~b}$ & 8,17 & 65,17 & 6,94 \\
\hline Centro (T4) & $101,21 \mathrm{~b}$ & 8,67 & 53,92 & 7,13 \\
\hline Fundo (T5) & $79,17 \mathrm{~b}$ & 5,67 & 57,75 & 6,29 \\
\hline Esquerda (T6) & $105,17 \mathrm{~b}$ & 8,33 & 46,75 & 5,88 \\
\hline Centro (T7) & $131,80 \mathrm{a}$ & 8,33 & 74,92 & 8,06 \\
\hline Direita (T8) & $108,75 \mathrm{~b}$ & 9,00 & 55,00 & 6,65 \\
\hline Quadrante 1 (T9) & $169,08 \mathrm{a}$ & 8,33 & 54,50 & 6,39 \\
\hline Quadrante 2 (T10) & 149,17 a & 9,00 & 44,08 & 6,21 \\
\hline Quadrante 3 (T11) & $110,92 \mathrm{~b}$ & 8,00 & 43,75 & 6,32 \\
\hline Quadrante 4 (T12) & $112,25 \mathrm{~b}$ & 9,17 & 50,92 & 6,25 \\
\hline Média & 111,28 & 7,43 & 57,38 & 6,82 \\
\hline $\mathrm{CV}(\%)$ & 39,38 & 34,48 & 33,64 & 26,64 \\
\hline
\end{tabular}

*Médias dos tratamentos com letras diferentes, dentro de cada variável em cada ambiente de produção, diferem pelo teste Scott-Knott em nível de 5\% de probabilidade de erro; ns: não significativo

inverno, verifica-se situação semelhante para a mesma variável avaliada, onde o tratamento centro T2 de maior média (139,95 gramas - Tabela 3), não resultou na maior variância obtida (346,09 - Tabela 1). Nos experimentos com produção de mudas, esperava-se que as melhores médias fossem oriundas das posições centrais das bandejas, ou seja, os tratamentos T2, T4 e T7, que resultariam em maior crescimento e melhor desenvolvimento em razão de apresentarem elevado teor de umidade no substrato em relação às repetições das bordaduras das bandejas. $\mathrm{O}$ tratamento centro $\mathrm{T} 2$ apresentou esse resultado nas quatro variáveis avaliadas mantendo essa condição (Tabela 2). No entanto, o tratamento frente (T3) que não pertence à posição central também apresentou médias elevadas. Essas diferenças entre as médias provavelmente foram oriundas das diferentes condições fisiológicas das 
sementes, proporcionando pequena desuniformidade na germinação e emergência, acarretando em competição da parte aérea das mudas na bandeja. Também se deve considerar que coleta das mudas nas repetições avaliadas foram realizadas ao acaso, ou seja, uma muda pertencente a uma repetição da bordadura nem sempre era retirada da última fileira dos alvéolos, as quais apresentavam maior demanda evapotranspirativa e, conseqüentemente, menor teor de umidade no substrato e absorção de água pela sementes e plântulas.

Analisando os experimentos de produção de plantas, percebe-se que as melhores médias obtidas não correspondem à mesma sequência das posições avaliadas nos experimentos de produção de mudas, nas mesmas variáveis entre os ambientes. Essas diferenças podem ser atribuídas a diversos fatores tais como a variação na concentração de fertilizantes no solo, às variações provocadas pelo manejo empregado (transplante, aplicação de fertilizantes, entre outros) e localização das plantas no ambiente de cultivo, ou seja, a proximidade destas com as laterais (no ambiente estufa plástica), bem como a interferência da heterogeneidade do solo e os diferentes níveis de luminosidade incidentes no dossel vegetativo. Essas proposições estão de acordo com os resultados obtidos por Boligon (2007), que verificou a mesma situação para a cultura do pimentão em estufa plástica. Também trabalhando com pimentão, Lorentz et al. (2004) relatam que a radiação solar global e a temperatura do ar, consequentemente, podem atuar de maneira distinta nos diferentes locais dentro da estufa contribuindo nas diferenças entre as médias de produção das plantas.

As plantas cultivadas em estufa plástica apresentaram maior produção de FFPA e FSPA em relação ao campo (Tabela 3). Esses resultados concordam com os obtidos por Radin et al. (2004) e Segovia et al. (1997) que verificaram que o número de folhas emitidas e a taxa de crescimento das plantas foram maiores em ambiente protegido quando compararam o crescimento e o desenvolvimentodealgumascultivaresdealface.Estudando a taxa de crescimento da cultura do alface em ambientes naturais e protegidos, Dantas e Escobedo (1998) também verificaram diferenças entre os ambientes, mostrando que a fitomassa seca no verão foi maior, com superioridade de aproximadamente $69 \%$ nos ambientes protegidos e de $60 \%$ na parcela externa, refletindo no rendimento final da cultura. Esse comportamento diferenciado pode ser atribuído a fatores de manejo e ambiente de produção $\mathrm{e}$, especialmente, às modificações meteorológicas nos diferentes ambientes testados. Observou-se que no verão as temperaturas mínimas, máximas e médias do ar e o brilho solar foram maiores em relação à estação outono-inverno (Figura 2). Como no interior da estufa a temperatura máxima do ar é maior, sendo a mínima praticamente igual à do ambiente externo, a amplitude térmica diária verificada no ambiente protegido é maior em relação ao ambiente externo (FARIAS et al., 1993 e MONTERO et al., 1985) influenciando diretamente na soma térmica que interferiu no acúmulo diferenciado de fitomassa da cultura entre os ambientes, independente da época de cultivo (Tabela 3 ).

\section{Conclusões}

1. Há atendimento das pressuposições de homogeneidade e normalidade dos erros experimentais para as fitomassas fresca da parte aérea e de raiz de alface nos experimentos com diferentes posições de mudas na bandeja de produção, nos diferentes ambientes e estações sazonais de cultivo.

2. Para a fitomassa seca da parte aérea não há atendimento das pressuposições de homogeneidade e/ou normalidade dos erros experimentais nos experimentos no verão, com produção de mudas e de plantas na estufa plástica.

3. Para a fitomassa seca de raiz não há atendimento da pressuposição da normalidade dos erros experimentais no experimento no outono-inverno com produção de mudas.

\section{Agradecimentos}

Ao $\mathrm{CNPq}$ pela concessão de auxílio financeiro para a realização dos experimentos e pelas bolsas de produtividade em pesquisa e iniciação científica.

\section{Referências}

ANDRIOLO, J. L.; ESPÍNDOLA, M. C. G.; STEFANELLO, M. O. Crescimento e desenvolvimento de plantas de alface provenientes de mudas com diferentes idades fisiológicas. Ciência Rural, v. 33, n. 01, p. 35-40, 2003.

BACKES, F. A. A. L. et al. Reposição de nutrientes durante três cultivos de alface em hidroponia. Horticultura Brasileira, v. 21, n. 04, p. 590-596, 2003.

BANZATTO, D. A.; KRONKA, S. N. Experimentação agrícola. 3. ed. Jaboticabal: FUNEP, 1995. 247 p.

BOLIGON, A. A. Variabilidade espacial do ponto de colheita e do crescimento de frutos de pimentão em estufa plástica. 2007. 76 f. Dissertação (Mestrado em Agronomia) - Universidade Federal de Santa Maria, Santa Maria, 2007.

CAMPOS, H. Estatística experimental não-paramétrica. 4. ed. Piracicaba: Departamento de Matemática e estatística ESALQ, 1983. 349 p. 
CARPES, R. H. et al. Ausência de frutos colhidos e suas interferências nas estimativas da fitomassa de frutos de abobrinha italiana cultivada em diferentes sistemas de irrigação. Revista Ceres, v. 55, n. 06, p. 590-595, 2008

SOCIEDADE BRASILEIRA DE CIÊNCIA DO SOLO (SBCS). COMISSÃO DE QUÍMICA E FERTILIDADE DO SOLO. Manual de adubação e calagem para os Estados do Rio Grande do Sul e Santa Catarina. Porto Alegre, 2004. 400 p.

DANTAS, R. T.; ESCOBEDO, J. F. Índices morfofisiológicos e rendimento da alface (Lactuca sativa $\mathrm{L}$.) em ambientes natural e protegido. Revista Brasileira de Engenharia Agrícola e Ambiental, v. 02, n. 01, p. 27-31, 1998.

EMPRESABRASILEIRADEPESQUISA AGROPECUÁRIA (EMBRAPA). Centro Nacional de Pesquisa de Solos. Sistema Brasileiro de Classificação de Solos. Brasília: EmbrapaSPI, 1999. $412 \mathrm{p}$.

FARIAS, J. R. B.; BERGAMASCHI, H.; MARTINS, S. R. Efeito da cobertura plástica de estufa sobre a radiação solar. Revista Brasileira de Agrometeorologia, v. 01, n. 01, p. 31-36, 1993.

FEIJÓ, S. et al. Heterogeneity index of zucchini yield on a protected environment and experimental planning. Horticultura Brasileira, v. 26, n. 01, p. 35-39, 2008.

GATES, D. M. et al. Spectral Properties of Plants. Disponível em: <http://www.opticsinfobase.org/abstract.cfm?URI=ao-4-111>. Acesso em: 25 jul. 2008.

GOTO, R. A. cultura da alface. In: GOTO, R.; TIVELLI, S. W. (Org.). Produção de hortaliças em ambiente protegido: condições subtropicais. São Paulo: UNESP, 1998. p. 137-159.

LOPES, S. J. et al. Técnicas experimentais para o tomateito tipo salada sob estufas plásticas. Ciência Rural, v. 28, n. 02, p. 193-197, 1998.

LORENTZ, L. H. et al. Variabilidade da produção de frutos de pimentão em estufa plástica. Ciência Rural, v. 35, n. 02, p. 316-323, 2005.

LORENTZ, L. H. et al. Variabilidade temporal do tamanho de amostra para experimentos em estufa plástica. Ciência Rural, v. 34, n. 04, p. 1043-1049, 2004.

LÚCIO, A. D. et al. Variância e média da massa de frutos de abobrinha-italiana em múltiplas colheitas. Horticultura Brasileira, v. 26, n. 03, p. 335-341, 2008.

LÚCIO, A. D. et al. Variação temporal da produção de pimentão influenciada pela posição e características morfológicas das plantas em ambiente protegido. Horticultura Brasileira, v. 24, n. 01, p. 31-35, 2006.

LÚCIO, A. D. et al. Estimativa de parâmetros para o planejamento de experimentos com a cultura do pimentão em área restrita. Horticultura Brasileira, v. 22, n. 04, p. 66-770, 2004.

LÚCIO, A. D. et al. Tamanho da amostra e método de amostragem para avaliação de características do pimentão em estufa plástica. Horticultura brasileira, v. 21, n. 02 p. 180-184, 2003.

MARODIM, V. S. et al. Delineamento experimental e tamanho de amostra para alface cultivada em hidroponia. Ciência Rural, v. 30, n. 05 , p. $779-781,2000$.

MARQUES, P. A. A. et al. Qualidade de mudas de alface formadas em bandejas de isopor com diferentes números de células. Horticultura Brasileira, v. 21, n. 04, p. 649-651, 2003.

MELLO, R. M. et al. Size and form of plots for the culture of the italian pumpkin in plastic greenhouse. Scientia Agricola, v. 61, n. 04, p. 457-461, 2004.

MONTERO, J. I. et al. Climate under plastic in the Almeria area. Acta Horticulturae, Wageningen, v. 170, p. 227-234, 1985.

MOREnO, J. A. Clima no Rio Grande do Sul. Porto Alegre: Secretaria da Agricultura, 1961. $41 \mathrm{p}$.

RADIN, B. et al. Crescimento de cultivares de alface conduzidas em estufa e a campo. Horticultura Brasileira, v. 22, n. 02, p. 178-181, 2004.

SEGOVIA, J. F. O. et al. Comparação do crescimento e desenvolvimento da alface (Lactuca sativa L.) no interior e no exterior de uma estufa de polietileno em Santa Maria, RS. Ciência Rural, v. 27, n. 01, p. 37-41, 1997.

SILVA, E. C.; LEAL, L. N.; MALUF, W. R. Avaliação de cultivares de alface sob altas temperaturas em cultivo protegido em três épocas de plantio na região Norte Fluminense. Ciência e Agrotecnologia, v. 23, n. 03, p. 491-499, 1999.

SOUZA, M. F. et al. Tamanho da amostra para peso da massa de frutos, na cultura da abóbora italiana em estufa plástica. Revista Brasileira de Agrociência, v. 08, n. 02, p. 131-136, 2002.

STELL, R. G. D.; TORRIE, J. H.; DICKEY, D. A. Principles and procedures of statistics: a biometrical approach. New York: McGraw-Hill Book, 1997. 666 p.

YURI J. E. et al. Alface americana: cultivo comercial. Lavras: UFLA, 2002. 51 p. (Texto acadêmico). 